\title{
A Structural Equation Model of Achievement Emotions, Coping Strategies and Engagement-Burnout in Undergraduate Students: A Possible Underlying Mechanism in Facets of Perfectionism
}

\author{
Jesús de la Fuente ${ }^{1,2, * \mathbb{D}}$, Francisca Lahortiga-Ramos ${ }^{3}$, Carmen Laspra-Solís ${ }^{3}$, \\ Cristina Maestro-Martín ${ }^{3}$, Irene Alustiza ${ }^{3}$, Enrique Aubá ${ }^{3}$ and Raquel Martín-Lanas ${ }^{3}$ \\ 1 School of Education and Psychology, University of Navarra, 31009 Pamplona, Spain \\ 2 School of Psychology, University of Almería, 04120 Almería, Spain \\ 3 Department of Psychiatry and Clinical Psychology, University Clinic of Navarra, 31008 Pamplona, Spain; \\ flahortiga@unav.es (F.L.-R.); claspra@unav.es (C.L.-S.); cmaestro@unav.es (C.M.-M.); ilalustiza@unav.es (I.A.); \\ eauba@unav.es (E.A.); rmlanas@unav.es (R.M.-L.) \\ * Correspondence: jdlfuente@unav.es
}

Received: 31 January 2020; Accepted: 19 March 2020; Published: 22 March 2020

check for updates

\begin{abstract}
Achievement emotions that the university student experiences in the learning process can be significant in facilitating or interfering with learning. The present research looked for linear and predictive relations between university students' achievement emotions, coping strategies, and engagement-burnout, in three different learning situations (classroom, study time, and testing). Hypotheses were identified for a possible model that would analyze the two facets of perfectionism based on these relations. In the case of perfectionistic strivings, the test hypothesis was that positive emotions would predispose the use of problem-focused coping strategies and an emotional state of engagement; in the case of perfectionistic concerns, however, negative emotions would predispose the use of emotion-focused strategies and a state of burnout. A total of 654 university students participated in the study, using an online tool to complete validated questionnaires on the three study variables. All students provided informed consent and corresponding permissions. Given the ex-post facto linear design, the predictions could be verified for each situation by means of logistic regression analyses and Structural Equations Models (SEM). Empirical results lent support, in varying degree, to the proposed theoretical relations. The testing situation was of particular interest. We discuss implications for perfectionism research and for the practice of prevention, education and health care in the university setting.
\end{abstract}

Keywords: achievement emotions; coping Strategies; engagement-burnout; university students; perfectionism

\section{Introduction}

The psychological well-being of college students is increasingly recognized as an important concern within higher education. The study of students' emotional experiences in the teaching-learning context has produced a great deal of research on aspects not previously considered under the cognitivist paradigm. Such research seeks to explain to what degree emotional processes facilitate or interfere in learning processes [1-7]. Specifically, the level of stress experienced by students who try to meet the demands and requirements of university study has captured the interest of researchers $[8,9]$. 
When considering academic stress, Clinical and Health Psychology give research priority to individual predictive or explanatory factors, such as personality variables, anxiety, and cognitive differences [10,11]. From the Educational Psychology perspective, however, academic stress can be considered a contextualized phenomenon within the learning process [12], especially in formal, high-pressure contexts. Classroom, study and testing situations represent an increasing progression of stressful stimuli, requiring college students to manage their emotions on a daily basis [13]. Emotions that are produced in these situations have a determining influence on students' well-being and achievement.

Depending on their individual characteristics, students in these contexts use different methods or coping strategies to manage stress [14]. Prior research has reported predictive relationships between self-regulation and coping strategies [15], and between resilience, coping and burnout [16]. However, the predictive relationship between achievement emotions and coping strategies has yet to be clearly established, as well as the effect of these two variables on the motivational state of engagement versus burnout in university students. This is therefore the focus of the present investigation. This relationship, moreover, may also be important in helping to clarify emotional mechanisms that are involved in the different types of perfectionism.

\section{Perfectionism as a Personal Academic Variable}

Academic perfectionism can be described as setting exceedingly high standards, then pursuing those standards with relentless self-criticism [17]. Reactivity to stress also seems to be influenced by perfectionism. Perfectionism as a multidimensional construct - with adaptive and maladaptive facets—has been supported by multiple studies over the past twenty years [18]:

1) Personal Standards Perfectionism (PSP), or perfectionistic strivings, is considered an adaptive aspect of perfectionism. The individual sets and pursues high standards and goals, a practice that has been associated with psychological wellbeing, as indicated by adaptive aspects including task-enjoyment, positive affect, and satisfaction [19].

2) Evaluative Concerns Perfectionism (ECP), or perfectionistic concerns, by contrast, constitute a maladaptive aspect of perfectionism. Unrealistically high standards and expectations are followed by overly critical self-assessment, negative reactions to failure, and preoccupation with criticism and expectations from others. Several studies find perfectionistic concerns to be associated with maladaptive indicators of psychological well-being: depression, distress, anxiety, and hopelessness [20,21]; reduced well-being, depression, burnout and anxiety [22,23], concern over mistakes, doubts about actions, socially prescribed perfectionism, discrepancy, and negative reactions to imperfections [24].

\subsection{Achievement Related Emotions as an Affective Variable of the Learning Process}

Achievement emotions, an affective component of learning, have become a specific topic of research interest. Based on Pekrun's control-value theory [25,26], achievement emotions are determined by the interaction of two components: the perceived controllability of achievement activities and their outcomes, and value appraisals of the subjective value or importance of these activities or outcomes. Academic emotions, more broadly, include achievement emotions experienced in an academic context, as well as any emotions related to (1) the instruction, (2) the study process, or (3) an exam situation [27-31]. These three types of situations are considered representative of the three levels of academic stress experienced by college students [25].

Pekrun [32] went beyond previous conceptualizations [33,34] to classify academic emotions along three axes: their focus, valence, and activation (for an overview, see [35]). The source (focus) of academic or achievement emotions can be either the: (a) activity, relating to ongoing activities involved in achieving, or the (b) outcome, pertaining to concerns about achievement outcomes [25]. For both activity and outcome emotions, their valence can be either positive or negative (pleasant or unpleasant), and their role in activation either activating or deactivating. Recent research addresses certain activity emotions in academic settings, for example: the positive, activating emotion of enjoyment (for an overview, see [26]) and the negative, deactivating emotion of boredom (for an overview, see [27]). 
In general, we assume that positive activating emotions (enjoyment, hope, pride) have a positive impact on achievement, while negative emotions (anger, anxiety, shame, hopelessness), and deactivating emotions (boredom, relief) negatively affect achievement and learning behavior. Empirical evidence supports this assumption, in classroom, study and exam situations $[28,29]$.

Recent research has supplied plentiful evidence on the role of achievement emotions in the university context [30]. Positive activating emotions (enjoyment, hope, pride) were reported to be interrelated with metacognitive monitoring processes in multimedia learning tasks, but negative emotions (frustration) and deactivating emotions (boredom) have been shown to negatively predict self-monitoring [31]. Elsewhere, the negative impact of test anxiety has been verified, and potential control mechanisms have been explored [32]. The effect of rumination on university students' negative affect and on their achievement has also been confirmed [33].

While research findings increasingly identify the specificities of academic emotions, there has been little attempt to search out the underlying mechanisms. Relationships between negative emotions and emotion-focused coping strategies have been reported in secondary education [34], but not at university. The present study contributes evidence in this direction, exploring how academic emotions in university students relate to their stress coping strategies; how emotions and coping strategies together affect motivational state (engagement versus burnout) and how they may also be an underlying mechanism in the two facets of perfectionism.

\subsection{Coping Strategies as a Meta-emotional Variable of the Learning Process}

Coping strategies are a psychological construction referring to strategic knowledge, skills and behaviors that people use to manage emotions in a given situation; they are thus conceptualized as meta-emotional skills [35]. Categorizations of coping vary substantially among researchers and theoretical orientations. In general, coping strategies tend to be grouped into categories according to the degree that the strategies are beneficial/adaptive or detrimental/maladaptive. Lazarus and Folkman [36] proposed an initial categorization of coping strategies that identifies two types of focus: (1) emotion-focused strategies that seek to manage, minimize or avoid negative emotional states (distraction, reducing anxiety, preparing for the worst, emotional venting, resigned acceptance); and (2) problem-focused strategies that manage or reduce the causes of the stressful experience or of overextended personal resources (help-seeking, self-instructions, positive reappraisal, social support, alternative reinforcement). While the first version of the Cognitive Theory of Stress and Coping [37] assumes that the state of stress is associated with negative emotions, the Revised Stress and Coping model [38] adopts the position that positive emotions and negative emotions co-occur in stress states [39].

Several studies have tried to identify strategies as being adaptive or maladaptive. Adaptive and maladaptive strategies have been identified in the literature on critical incident, traumatic stress, and occupational stress [40], including such examples as anger, distancing, planned effort, positive reappraisal, and social support [41], and maladaptive avoidant and ruminative coping [42].

Prior research on motivational-affective factors in university learning has also stressed the importance of particular aspects of how university students cope with stress: religious coping (Francis et al., 2018); the role of health habits as a coping strategy [43]; coping in relationship to well-being [44-46]. Also, have analyzed the predictive role of achievement emotions in coping strategies and in motivational states of engagement-burnout [47].

An analysis of predictive relations between academic emotions and coping strategies can help us establish mechanisms that then relate these to the motivational states of engagement or burnout. This relationship, in addition to its own relevance, could later be incorporated into models of positive and negative aspects of perfectionism, as described in sections above. 


\subsection{Engagement-Burnout as a Motivational Variable of the Learning Process}

The constructs of engagement and burnout are motivational-affective in nature and refer to a student's emotional state in an instructional context. The two constructs can be considered polar opposites, representing two extremes of the same aspect. While burnout represents fatigue, depersonalization, lack of expectations and disaffection for one's work [48], engagement represents a liking for, engagement and enjoyment of one's work [49]. Some recent studies express doubt as to whether the "engagement-burnout" construct constitutes a single dimension that goes from commitment (implication) to wear (attrition). Leiter and Maslach [50,51] themselves point out that the two constructs may be related, while not absolutely opposite of each other.

Previous research has reported factors that predict and predispose both constructs [52]. Achievement emotions (positive vs. negative) have been differentially associated with burnout [53], and engagement has been shown to favor metacognitive self-regulation and knowledge construction [54]. More recently, the duality has been conceptualized as positive learning or engagement vs. negative learning or burnout [55]. The importance of engagement has also been reported in service-learning situations at university [56]. Burnout, for its part, has consistently appeared as a negative predictor of motivation and achievement $[57,58]$; however, the inventory authors have recognized that the two constructs have a complex relationship, requiring more specific analyses by profiles [50,51]. Understanding the relationship of burnout-engagement to university students' achievement emotions and coping strategies would make it possible to assess the profile of these factors in the two facets of perfectionism.

\section{Aims and Hypotheses}

The existing theoretical models of learning-related emotions have not considered that types of achievement emotions (emotional variables) may be associated with types of coping strategies (meta-emotional variables), and that this may affect university students' state of engagement-burnout (motivational variable). A hypothetical relational model that incorporates achievement emotions, coping strategies, motivation, and facet of perfectionism is represented in Figure 1. Specifically, (1) ECP, representing negative reactions to failure and being overly self-critical, is typically associated with maladaptive outcomes, such as reduced well-being, depression, burnout and anxiety [22]; while (2) PSP, representing the setting of high standards and goals, is associated with adaptive indicators of psychological wellbeing, such as task-enjoyment, positive affect, and satisfaction [19].

Based on this proposed model, the aim of this research was to verify any linear, predictive relations between achievement emotions (emotional variable), coping strategies (meta-emotional variable) and engagement-burnout (motivational variable) in university students, during three different learning situations: the classroom, study time, and testing. Predictive, structural, linear relationships would allow us to verify the direct and indirect effects of certain variables on others. Specifically, they provide an explanatory, mediational empirical model of coping strategies with respect to the other two variables in each specific situation (class, study and testing). This represents a methodological advance, given that the predictive relationship, direct and indirect, cannot be identified using classic variance analyses. Consequently, we established these hypotheses: (H1) positive emotions will predispose the use of problem-focused coping strategies and an attitude/emotional state of engagement when learning; (H2) negative emotions will predispose the use of emotion-focused strategies, and an emotional state of burnout when learning. 


\begin{tabular}{lll}
\hline $\begin{array}{l}\text { Achievement } \\
\text { Emotions }\end{array}$ & $\begin{array}{l}\text { Coping } \\
\text { Strategies }\end{array}$ & $\begin{array}{l}\text { Motivational } \\
\text { State }\end{array}$ \\
\hline $\begin{array}{l}\text { Perfectionistic Concerts }(E C P): \\
\text { Negative emotions }-------\rightarrow\end{array}$ & Emotion-Focused Coping $-----------\rightarrow$ & Burnout \\
$\cdot$ Anger & $\cdot$ Distraction & Depletion \\
$\cdot$ Anxiety & $\cdot$ Reducing anxiety & Cynicism \\
$\cdot$ Shame & $\cdot$ Preparing for the worst & $\cdot$ Lack of effectiveness \\
$\cdot$ Hopelessness & $\cdot$ Emotional venting & \\
& $\cdot$ Resigned acceptance &
\end{tabular}

Perfectionism Striving (PSP):

Positive emotions $-------\rightarrow$
$\cdot$ Enjoyment
$\cdot$ Hope
$\cdot$ Pride

$\begin{array}{ll}\text { Problem-Focused Coping ------------ } \rightarrow & \text { Engagement } \\ \cdot \text { Help-seeking } & \cdot \text { Vigor } \\ \cdot \text { Self-instructions } & \cdot \text { Dedication } \\ \cdot \text { Positive reappraisal } & \cdot \text { Absorption }\end{array}$

-Social support

-Alternative reinforcement

Figure 1. Relationship model between achievement emotions, coping strategies and engagement-burnout, based on the preview model [52] (pp. 151-152).

\section{Method}

\subsection{Participants}

Drawing from the two universities participating in this research project, a convenience sample was formed of students who completed the questionnaires. There were 642 undergraduate students from the two Spanish universities, and ten teaching and learning processes (from ten academic subjects) were assessed. The sample was composed of students enrolled in Psychology and Primary Education degree programs; $83.5 \%$ were women and 16.5\% were men. Their ages ranged from 19 to 45 years, with a mean age of $20.13(s d=5.8)$ years. Participation was anonymous and voluntary. The Guidance Department at each university extended an invitation to participate to the teachers in the relevant departments, and the participating teachers offered the invitation to their students. Teacher and student participation was recognized with the Certificate of Participation in an R\&D Project. Each academic subject (specific teaching-learning process) was assessed through online questionnaires.

\subsection{Instruments}

Achievement Emotions. The Achievement Emotions Questionnaire, AEQ [29] is a multi-dimensional self-report instrument that assesses achievement emotions in university students. The questionnaire was generated as part of a quantitative and qualitative research program that analyzed emotions experienced by students in academic achievement situations (for a summary, see [13]). Several discrete emotions are measured in the context of the three main situations pertaining to academic achievement: attending class, studying, and completing tests and exams. The AEQ in its current version measures eight class-related emotions, eight study-related emotions, and eight emotions during testing. Thus, the three sections of the AEQ correspond to these situations of classroom, study time, and testing. The class-related emotions scale (CRE) contains 80 items that measure the following eight emotions: class-related enjoyment, hope, 
pride, anger, anxiety, shame, hopelessness, and boredom. The learning-related emotions scale (LRE) uses 75 items to measure the same eight emotions in study situations. The test emotions scale (TES) contains 77 items for assessing test-related enjoyment, hope, pride, relief, anger, anxiety, shame, and hopelessness. Each section contains three sub-sections that address the emotions felt before, during and after the academic situation covered by that section. The student's trait achievement emotions are assessed, in other words, his or her typical personal emotional reactions to achievement situations. Instructions for the AEQ can be modified in order to measure emotions experienced in a particular class subject (course-specific emotions), or in specific situations at specific moments (state achievement emotions).

The AEQ measures four positive emotions (enjoyment, hope, pride, and relief) and five negative emotions (anger, anxiety, hopelessness, shame, and boredom). Two main criteria were used for deciding what emotions to include. First, emotions frequently experienced by college students were identified [25]. Second, the emotions were classified along two dimensions, each having two possible values: valence (positive vs. negative) and activation (activating vs. deactivating) (see $[53,54]$ ). Four categories of emotions result from the combination of these values, and reflect how emotions affect learning, achievement, personality development, and health. The resulting categorizations are: positive activating: enjoyment, hope, pride; positive deactivating: relief; negative activating: anger, anxiety, shame, hopelessness; negative deactivating: boredom.

There are differences in the function and social structure of the three basic types of university achievement situations (attending class, studying, and taking tests). Consequently, the emotions experienced in these situations also differ. For example, enjoying classroom instruction is not the same as enjoying the challenge of an exam. While some students may feel excited about going to class, others feel excited when facing a test. This is taken into account in the AEQ through separate scales for emotions relating to the class setting, study time, and testing:

1) Class-Related Emotions (translation: [55]). CRE psychometric properties were found to be satisfactory in students from Spain. The model obtained good fit indices in this sample. Also verified were unidimensionality of the scale and metric invariance in the samples evaluated (Chi Square $=$ 10885.597, Degrees of freedom $=3052, p<0.001 ; \mathrm{CFI}=0.951, \mathrm{TLI}=0.952, \mathrm{IFI}=0.963, \mathrm{TLI}=0.958$, and $\mathrm{CFI}=0.952 ;$ RMSEA $=0.041 ;$ HOELTER $=458, p<0.05 ; 466 p<0.01)$. Cronbach's alpha for this sample was 0.904 , with 0.803 ( 40 items) and 0.852 (40 items) for the two parts, respectively ( 80 items).

2) Learning-Related Emotions (translation: [56]). LRE psychometric properties were found to be satisfactory in students from Spain. The model obtained good fit indices in this sample. Also verified were unidimensionality of the scale and metric invariance in the samples evaluated (Chi Square $=$ 10885.597, Degrees of freedom $=3052, p<0.001 ; \mathrm{CFI}=0.959, \mathrm{TLI}=0.942, \mathrm{IFI}=0.969, \mathrm{TLI}=0.955$, and CFI $=0.958$; RMSEA $=0.038$; HOELTER $=501, p<0.05 ; 511 p<0.01)$. Cronbach's alpha for this sample was 0.930 , with 0.880 ( 38 items) and 0.846 ( 37 items) for the two parts, respectively (75 items).

3) Test-Related Emotions (translation: [56]). TRE psychometric properties were found to be satisfactory in students of Spain. The model obtained good fit indices in this sample. Also verified were unidimensionality of the scale and metric invariance in the samples evaluated (Chi Square = 10885.597, Degrees of freedom $=3052, p<0.001 ; \mathrm{CFI}=0.954, \mathrm{TLI}=0.946, \mathrm{IFI}=0.964, \mathrm{TLI}=0.959$, and CFI $=0.953$; RMSEA $=0.039 ;$ HOELTER $=492, p<0.05 ; 502 p<0.01)$. Cronbach's alpha for this sample was 0.913 , with 0.824 and 0.869 for the two parts, respectively (77 items).

Coping Strategies (meta-emotional variable). To measure coping strategies, we used the EEC-Short [57], a short, validated Spanish version of the Coping Strategies Scale, EEC [58]. While the original instrument contained 90 items, the validation produced a first-order structure of 64 items and a second order with 10 factors and two significant dimensions, the latter having adequate fit values [(Chi-square $=878.750 ;$ Degrees of freedom $(77-34)=43, \mathrm{p}<0.001$; NFI $=0.901 ; \mathrm{RFI}=0.945 ; \mathrm{IFI}=0.903, \mathrm{TLI}$ $=0.951, \mathrm{CFI}=0.903, \mathrm{RMSEA}=0.07]$. For reliability measures, Cronbach alpha values were 0.93 (complete scale), 0.93 (first half) and 0.90 (second half), Spearman-Brown was 0.84 and Guttman was 0.80. Two dimensions are evaluated: D1. Emotion-focused coping (0.95); D2. Problem-focused coping 
(0.91). The emotion-focused strategies were: F1. Avoidant distraction (0.79); F7. Reducing anxiety and avoidance (0.88); F8. Preparing for the worst (0.80); F9. Emotional venting and isolation (0.91); and F10. Resigned acceptance (0.86). Problem-focused strategies were: F2. Seeking family help and counsel (0.92); F5. Self-instructions (0.82); F10. Positive reappraisal and firmness (0.87); F12. Communicating feelings and social support (0.89); and F13. Seeking alternative reinforcements 0.80$)$. See Table 1.

Table 1. Types of Coping Strategies and Examples of Items in the Short EEC version [56].

\begin{tabular}{|c|c|}
\hline Emotion-focused coping (D1) & Example items \\
\hline F1. Avoidant distraction & I sleep more than usual \\
\hline F7. Reducing anxiety and avoidance & $\begin{array}{l}\text { I decrease my anxiety by avoiding or escaping from situations that } \\
\text { provoke it }\end{array}$ \\
\hline F8. Preparing for the worst & I prepare myself for the worst \\
\hline F9. Emotional venting and isolation & I act irritable and aggressive toward others \\
\hline F11. Resigned acceptance & I accept the problem as it is, since I cannot do anything to solve it \\
\hline Problem-focused coping (D2) & Example items \\
\hline F2. Seeking help and family advice & I ask a friend to help me clarify how I ought to tackle my problems \\
\hline F5. Self-Instructions & I set down a plan of action and try to carry it out \\
\hline F10. Positive reappraisal and firmness & I try to see positive aspects of the situation \\
\hline F12. Comunicating feelings and social support & I feel better if I explain my problem to friends or family members \\
\hline F13. Seeking alternative reinforcement & I start new activities (studies, etc.) \\
\hline
\end{tabular}

Engagement-Burnout. Cross-cultural studies have shown adequate reliability and construct validity indexes for this construct. A validated Spanish version of the Utrecht Work Engagement Scale for Students [59] was used to assess Engagement. The psychometric properties were satisfactory in students from Spain. The model obtained good fit indices in this sample, with a second-order structure of three factors: vigor, dedication and absorption. Also verified were unidimensionality of the scale and metric invariance in the samples evaluated [Chi Square $=792.526, d f=74, p<0.001 ; \mathrm{CFI}=0.954$, TLI= 0.976, IFI= 0.954, TLI= 0.979, and CFI= 0.923; RMSEA= 0.083; HOELTER $=153, p<0.05 ; 170 p<$ 0.01]. Cronbach's alpha for this sample was 0.900 ( 14 items), with 0.856 ( 7 items) and 0.786 (7 items) for the two parts, respectively.

The validated Spanish version of The Marlach Burnout Inventory, MBI [60] was also used to assess Burnout. Psychometric properties for this version were satisfactory in students from Spain. The model obtained good fit indices in this sample, with a second-order structure of three factors: exhaustion or depletion, cynicism, and lack of effectiveness. Also verified were unidimensionality of the scale and metric invariance in the samples evaluated [Chi Square $=767.885, d f=87, p<0.001$; CFI $=0.956$, TLI $=$ 0.964, IFI $=0.951, \mathrm{TLI}=0.951$, and CFI $=0.953$; RMSEA $=0.071 ;$ HOELTER $=224, p<0.05 ; 246 p<0.01]$. Cronbach's alpha for this sample was 0.874 (15 items), with 0.853 (8 items) and 0.793 (7 items) for the two parts, respectively.

\subsection{Procedure}

Participants voluntarily completed the scales using an online platform [61] [http://www. estres.investigacion-psicopedagogica.com/english/seccion.php?idseccion=1]. All students gave their informed consent through an online signature that is required when creating an account on the platform, before any questionnaires are completed. Ten specific teaching-learning processes were evaluated, covering different university subjects over a two-year period. To avoid fatigue, students were asked to complete just one questionnaire at a time, at two different times each week, over a four-month period. They were awarded a Certificate of Participation in Research as an incentive to maintain their motivation and recognize their effort. Presage variables (personality and others) were evaluated in September-October of 2017 and of 2018, Process variables (Academic Emotions) in February-March of 2018 and of 2017, and Product variables (Coping Strategies, Engagement-Burnout) in May-June of 2017 and of 2018. The procedure was approved by the respective Ethics Committees (ref. 2018.170), in the context of an R \& D Project (2018-2021). 


\subsection{Data Analysis}

In order to address the objectives and linear hypotheses, we used an ex post facto design for linear (noncausal) prediction. The hypotheses were tested using (1) multiple linear regression analysis and (2) three SEM (Structural Equation Models) analyses. In both cases, they were tested for each of the three situations of stress: classroom, study time and testing. The database had initially been reviewed and any incomplete cases were eliminated. (1) Multiple regression analysis was conducted using SPSS (IBM; v.25.0). Bivariate correlational analyses were not carried out, as they are more limited when establishing multiple linear prediction. (2) Structural validity analysis was conducted using AMOS (v. 23.0) for Windows, as was construction of the structural prediction model, specifically, verification of the structural linear prediction hypothesis (path analysis). The Comparative Fit Index (CFI) and the Root Mean Square Error of Approximation (RMSEA) were used to interpret the confirmatory factor analysis (CFA) and fit of the structural equation model (SEM). CFI values were used to identify acceptable and close fit to the data, namely, values equal to or more than 0.90 and 0.95 , respectively [62]. RMSEA values equal to or below 0.05 and 0.08 , respectively, were taken to indicate close and acceptable levels of fit [63]. [Research has identified cutoff points in the form of beta coefficients for qualifying direct effects: less than 0.05 is considered too small to be meaningful, above 0.05 is small but meaningful, above 0.10 is moderate, and above 0.25 is large [64]. For indirect effects, we used Kenny's definition [65] of an indirect effect as the product of two effects. Following Keith's benchmarks, we proposed an educationally meaningful, small indirect effect $=0.003$, moderate $=0.01$, and large $=0.06$.

\section{Results}

\subsection{Linear Predictive Relationships}

The multiple regression analyses showed different significant relationships between achievement emotions, coping strategies and engagement-burnout attitudes in each situation:

\subsubsection{Classroom Situation}

In the classroom situation, overall, positive emotions were a statistically significant predictor of problem-focused strategies, while negative emotions predicted emotion-focused strategies. In the case of positive emotions, the emotion of hope was particularly powerful in negatively predicting strategies F9 (Emotional venting and isolation) and F11 (Resigned acceptance) and positively predicting all the problem-focused strategies, especially strategy F10 (Positive reappraisal and firmness). The emotion of pride predicted certain problem-focused strategies like F12 (Communicating feelings and social support) and F13 (Seeking alternative reinforcement). In the case of negative emotions, the emotion of anger positively predicted strategy F9 (Emotional venting and isolation) and negatively predicted problem-focused strategies, such as F2 (Seeking help and family advice) and F12 (Communicating feelings and social support). In addition, the emotion of boredom, as a negative, deactivating emotion, had power for predicting emotion-focused strategies in the case of F1 (Avoidant distraction), F7 (Reducing anxiety and avoidance) and F8 (Preparing for the worst). However, the emotion with the greatest predictive power was anxiety, with predictions similar to those of boredom, favoring the use of emotion-focused strategies F1, F7 and F8, but also problem-focused strategies F2 and F12. Shame significantly predicted strategies F9 (Emotional venting and isolation) and F11 (Resigned acceptance). For its part, hopelessness negatively predicted F7 (Reducing anxiety) and F5 (Self-instructions). See Table 2. 
Table 2. Linear regression coefficients (Beta) between Achievement Emotions (IV) and Coping Strategies (DV) with levels of stress (Class = level 1; Study = level 2; Test = level 3).

\begin{tabular}{|c|c|c|c|c|c|c|c|c|c|c|}
\hline Class & Positive & Negative & Enjoy & Hope & Pride & Boredom & Anger & Anxiety & Shame & Hopelessness \\
\hline Total & $0.378^{* *}$ & $0.291^{* *}$ & & $0.209^{* *}$ & $0.251^{* *}$ & & & & & \\
\hline D1 & $0.203^{* *}$ & $0.365^{* *}$ & & & & $0.253^{* *}$ & $0.215^{* *}$ & & & \\
\hline D2 & $0.412 * *$ & & & $0.469 * * *$ & & & & $0.220 * *$ & & \\
\hline F1 & $0.136^{*}$ & $0.246^{* *}$ & & & & $0.168 *$ & & $0.205^{* *}$ & & \\
\hline F7 & & $0.171 *$ & & & & $0.206^{* *}$ & & $0.202 * *$ & & $-0.218^{* *}$ \\
\hline F8 & & $0.341 * *$ & & & & $0.185^{* *}$ & & $0.259 * *$ & & \\
\hline F9 & & $0.417^{* * *}$ & & $-0.242^{* *}$ & & & $0.200^{* *}$ & & $0.158^{* *}$ & \\
\hline F11 & & $0.353 * *$ & & $-0.232 * *$ & & & & & $0.236^{* *}$ & \\
\hline F2 & $0.278 * *$ & & & $0.367^{* * * *}$ & & & $-0.0192 *$ & $0.233 * *$ & & \\
\hline F5 & $0.358^{* * *}$ & & & $0.286^{* * *}$ & & & & & & $-0.162 *$ \\
\hline F10 & $0.423^{* *}$ & & & $0.510^{* * *}$ & & & & & & \\
\hline F12 & $0.253^{* * *}$ & & $-0.323^{* * *}$ & $0.321 * *$ & $0.246^{* *}$ & & -0.231 ** & $0.222 * *$ & & \\
\hline F13 & & & & $0.265^{* *}$ & $0.172^{* *}$ & & & & & \\
\hline Study & Positive & Negative & Enjoy & Hope & Pride & Boredom & Anger & Anxiety & Shame & Hopelessness \\
\hline Total & $0.502 * * *$ & $0.380 * * *$ & & $0.203 *$ & 0.193 * & & & & & \\
\hline D1 & $0.283^{* * *}$ & $0.413^{* * *}$ & & & & $0.221^{* *}$ & & & $0.211^{* *}$ & \\
\hline $\mathrm{D} 2$ & $0.515^{* * *}$ & $0.145^{* *}$ & & $0.308^{* * *}$ & & & & & 0.183 * & $-0.193 *$ \\
\hline $\mathrm{F} 1$ & 0.124 * & $0.246^{* * *}$ & & & & & & & & \\
\hline F7 & & $0.234^{* * *}$ & & & & $0.252 * *$ & & $0.235^{* *}$ & & \\
\hline F8 & $0.141^{* *}$ & $0.417^{* * *}$ & & & $0.169 *$ & & & & 0.183 * & $0.257^{* *}$ \\
\hline F9 & & $0.419^{* * *}$ & & & & & & & & $0.330^{* * *}$ \\
\hline F11 & & 0.333 ** & & $-0.159 *$ & & & & & & $0.475^{* * *}$ \\
\hline F2 & $0.370 * *$ & $0.213 *$ & & & 0.163 * & $0.165 *$ & -0.228 ** & $0.205 *$ & 0.175 * & \\
\hline F5 & $0.491^{* * *}$ & & & 0.120 * & $0.235^{* *}$ & & & & & \\
\hline F10 & $0.434^{* * *}$ & & & $0.192^{* *}$ & $0.404^{* * *}$ & & & & & \\
\hline F12 & $0.332 * *$ & & & & & $0.249 * *$ & $-0.185^{*}$ & & $0.204^{* *}$ & \\
\hline F13 & $0.378^{* * *}$ & $0.245^{* *}$ & & $0.344^{* *}$ & & & & & 0.185 * & \\
\hline
\end{tabular}


Table 2. Cont.

\begin{tabular}{|c|c|c|c|c|c|c|c|c|c|c|}
\hline Testing & Positive & Negative & Enjoy & Hope & Pride & Relief & Anger & Anxiety & Shame & Hopelessness \\
\hline Total & $0.348^{* * *}$ & $0.255^{* * *}$ & & $0.268 * *$ & 0.205 * & & $0.214^{*}$ & & & \\
\hline D1 & $0.161 *$ & $0.289^{* * *}$ & & & & & & & & \\
\hline D2 & $0.385^{* * *}$ & & & & $0336^{* * *}$ & $0.265^{* *}$ & $0.231^{* *}$ & & & \\
\hline F1 & & $0.183^{* * *}$ & & & & & 0.172 * & & & \\
\hline F7 & & $0.147^{* *}$ & & & & & -0.142 * & & & \\
\hline F8 & & $0.308^{* * *}$ & & & & & 0.186 * & & & \\
\hline F9 & & $0.331^{* * *}$ & $0.229^{* *}$ & & & & $0.176^{*}$ & & & \\
\hline F11 & $-0.118^{*}$ & $0.334^{* * *}$ & & & $-0.260^{* *}$ & & & 0.175 * & & \\
\hline $\mathrm{F} 2$ & $0.212 * *$ & $0.113 *$ & & & $0.222 *$ & & & $0.196^{* *}$ & & \\
\hline F5 & $0.334^{* * *}$ & & & $0.380 * * *$ & & & & & & \\
\hline F10 & $0.336^{* * *}$ & 0.110 * & & $0.419 * * *$ & & & & $-0.252 * *$ & & \\
\hline F12 & $0.219 * *$ & 0.115 * & $-0.169 *$ & 0.179 * & $0.285^{* *}$ & & & $0.269 * *$ & & \\
\hline F13 & $0.284^{* * *}$ & 0.187 * & & 0.201 * & & & & 0.146 * & & \\
\hline
\end{tabular}

Note: Emotion-focused coping (D1): F1. Avoidant distraction; F7. Reducing anxiety and avoidance; F8. Preparing for the worst; F9. Emotional venting and isolation; F11. Resigned acceptance; Problem-focused coping (D2): F2. Seeking help and family advice; F5. Self-Instruction; F10. Positive reappraisal and firmness; F12. Communicating feelings and social support;

F13. Seeking alternative reinforcement. ${ }^{*} p<0.05 ; * * 0<0.01 ; * * * 00.001$ 


\subsubsection{Study Situation}

In the study situation, positive emotions positively predicted the use of all problem-focused strategies and certain emotion-focused strategies (F1 and F8), while negative emotions were positive predictors of all emotion-focused strategies and inversely predicted certain problem-focused strategies (F2 and F13). Specifically, the emotion of enjoyment positively predicted strategies F5 (Self-instructions) and F10 (Positive reappraisal and firmness). The emotion of hope significantly and positively predicted most problem-focused strategies and negatively predicted the emotion-focused strategy F11 (Resigned acceptance). The emotion of pride positively predicted strategies relating to social support, focused on the problem, as in F2 (Seeking help and family advice) and F12 (Communicating feelings and social support), as well as focused on emotion, as in F8 (Preparing for the worst). Also in this situation, the negative deactivating emotion of boredom was a strong negative predictor of problem-focused strategies F2 (Seeking help and family advice) and F10 (Positive reappraisal and firmness), and positive predictor of the emotion-focused strategy F7 (Reducing anxiety and avoidance). The negative emotion predicting the second highest number of strategies was anxiety, which predicts both problem-focused strategies (F7, F8) and emotion-focused strategies (F2, F12, F13). However, shame predicted only emotion-focused strategies (F8, F9, F11). See Table 2.

\subsubsection{Testing Situation}

In the testing situation, while positive emotions predicted the use of problem-focused strategies, negative emotions predicted both emotion-focused strategies and problem-focused strategies, although predictive strength was greater in the emotion-focused strategies. One effect not observed in the other situations was that enjoyment significantly predicted the emotion-focused strategy F9 (Emotional venting and isolation). Also in this situation, the positive emotion hope positively and significantly predicted most problem-focused strategies (F10, F4, F12, F13), while pride showed less positive predictive power (F12, F2). The negative, deactivating emotion of boredom had no predictive value in this situation. The negative emotion of anger negatively predicted strategy F10 (Positive reappraisal and firmness), but positively predicted the emotion-focused strategy F9 (Emotional venting and isolation), as well as certain problem-focused strategies (F12 and F13). The negative emotion of anxiety proved to be a positive, significant predictor of strategy F11 (Resigned acceptance) and F2 (Seeking help and family advice). Finally, the emotions shame and hopelessness were predictors of F1 (Avoidant distraction) and F8 (Preparing for the worst).

One important effect to note is that in all three situations, total positive achievement emotions were a positive, significant predictor of problem-focused coping strategies F5 (Self-Instructions) and F10 (Positive reappraisal and firmness), while total negative achievement emotions were a positive, significant predictor of strategy F9 (Emotional venting and isolation). See Table 2.

\section{Structural Prediction Relationships}

\subsection{Multivariate Relation Pathway: Class Situation (Stress Level 1)}

The results of pathway analysis (SEM) showed an acceptable model of the relationship between variables. The relationship parameters of both models are set out below. Two models were tested; the second obtained more consistent results and was taken as definitive. See Table 3.

Table 3. Models of structural linear results of the variables.

\begin{tabular}{ccccccccc}
\hline $\mathbf{C h i}^{2} \quad$ FG & $p<$ & NFI & RFI & IFI & TLI & CFI & HOELT. & RMSEA \\
\hline $\begin{array}{c}\text { Model 4229.258 } \\
\text { (324-382): } 242\end{array}$ & 0.000 & 0.799 & 0.826 & 0.811 & 0.840 & 0.810 & 0.189 & 0.103 \\
\hline $\begin{array}{c}\text { Model 4417.851 } \\
\text { (324-380): } 224\end{array}$ & 0.000 & 0.908 & 0.913 & 0.907 & 0.926 & 0.906 & 0.206 & 0.085 \\
\hline
\end{tabular}


Standardized Direct Effects. This predictive linear model establishes that lack of positive emotions (POS) negatively predicted $(-0.28)$ problem-focused strategies (PROB), and was a negative predictor of (0.20) engagement (ENG); this lack also positively predicted (0.52) negative emotions (NEGAT) and burnout (0.24) (BURN). Negative emotions (NEGAT) more strongly predicted (0.56) emotion-focused strategies (EMOT), which in turn were positive predictors (0.26) of burnout (BURNT); they were also negative predictors (-0.44) of engagement (ENG). Consequently, burnout (BURNT) was predicted by an absence of positive emotions (POS) and the presence of negative emotions (NEGAT), in conjunction with emotion-focused strategies (EMOT). See Table 4.

Table 4. Standardized Direct Effects (Default model). Class situation.

\begin{tabular}{|c|c|c|c|c|c|c|}
\hline & POSIT & NEGAT & PROB & EMOT & ENGAGEMENT & BURNOUT \\
\hline NEGATIVE & 0.525 & & & & & \\
\hline PROBLEM & -0.279 & & & & & \\
\hline EMOTION & & 0.562 & & & & \\
\hline ENGAGEMENT & & -0.444 & 0.200 & & & \\
\hline BURNOUT & 0.237 & & & 0.290 & -0.720 & \\
\hline ENJOYMENT & -0.856 & & & & & \\
\hline HOPE & -0.900 & & & & & \\
\hline PRIDE & -0.827 & & & & & \\
\hline BOREDOM & 0.569 & & & & & \\
\hline ANGER & & 0.809 & & & & \\
\hline ANXIETY & & 0.849 & & & & \\
\hline SHAME & & 0.701 & & & & \\
\hline HOPELESSNESS & & 0.910 & & & & \\
\hline EEF2 & & & 0.939 & & & \\
\hline EEF5 & & & 0.337 & & & \\
\hline EECF10 & & & 0.258 & & & \\
\hline EECF12 & & & 0.862 & & & \\
\hline EECF13 & & & 0.563 & & & \\
\hline EECF1 & & & & 0.462 & & \\
\hline EEFC7 & & & & 0.485 & & \\
\hline EECF8 & & & & 0.599 & & \\
\hline EECF9 & & & & 0.700 & & \\
\hline EECF11 & & & & 0.713 & & \\
\hline VIGOR & & & & & 0.829 & \\
\hline DEDICATION & & & & & 0.722 & \\
\hline ABSORPTION & & & & & 0.730 & \\
\hline EXHAUSTION & & & & & & 0.664 \\
\hline CYNICISM & & & & & & 0.655 \\
\hline LACK OF & & & & & & 0.717 \\
\hline EFFECTIVENESS & & & & & & 0.717 \\
\hline
\end{tabular}

Note: (D2) Problem-focused coping: F2. Seeking help and family advice; F5. Self-Instruction; F10. Positive reappraisal and firmness; F12. Communicating feelings and social support; F13. Seeking alternative reinforcement; (D1) Emotion-focused coping: F1. Avoidant distraction; F7. Reducing anxiety and avoidance; F8. Preparing for the worst; F9. Emotional venting and isolation; F11. Resigned acceptance.

Standardized Indirect Effects. The model also contributed multiple indirect predictions among the variables. Complementing the direct effects, lack of positive emotions also had indirect predictive effects on emotion-focused coping (0.295), negative effects on engagement $(-0.288)$ and positive on burnout (0.292). The absence of positive emotions positively predicted numerous negative emotions and emotion-focused coping strategies. Negative emotions also predicted coping strategies focused on emotion. Coping strategies focused on the problem positively predicted engagement, while emotion-focused strategies predicted burnout. See Table 5 . 
Table 5. Standardized Indirect Effects (Default model). Class Situation.

\begin{tabular}{|c|c|c|c|c|c|c|}
\hline & POSIT & NEGAT & PROB & EMOT & ENGAGEMENT & BURNOUT \\
\hline \multicolumn{7}{|l|}{ NEGATIVE } \\
\hline \multicolumn{7}{|l|}{ PROBLEM } \\
\hline EMOTION & 0.295 & & & & & \\
\hline ENGAGEMENT & -0.288 & & & & & \\
\hline BURNOUT & 0.292 & 0.482 & -0.143 & & & \\
\hline \multicolumn{7}{|l|}{ ENJOYMENT } \\
\hline \multicolumn{7}{|l|}{ HOPE } \\
\hline \multicolumn{7}{|l|}{ PRIDE } \\
\hline \multicolumn{7}{|l|}{ BOREDOM } \\
\hline ANGER & 0.424 & & & & & \\
\hline ANXIETY & 0.445 & & & & & \\
\hline SHAME & 0.367 & & & & & \\
\hline HOPELESSNESS & 0.477 & & & & & \\
\hline EEF2 & -0.262 & & & & & \\
\hline EEF5 & -0.094 & & & & & \\
\hline EECF10 & -0.072 & & & & & \\
\hline EECF12 & -0.241 & & & & & \\
\hline EECF13 & -0.157 & & & & & \\
\hline EECF1 & 0.136 & & & & & \\
\hline EEFC7 & 0.143 & & & & & \\
\hline EECF8 & 0.177 & & & & & \\
\hline EECF9 & 0.206 & & & & & \\
\hline EECF11 & 0.210 & & & & & \\
\hline VIGOR & -0.239 & -0.368 & 0.165 & & & \\
\hline DEDICATION & -0.208 & -0.320 & 0.144 & & & \\
\hline ABSORPTION & -0.211 & -0.324 & 0.146 & & & \\
\hline EXHAUSTION & 0.352 & 0.320 & -0.095 & 0.193 & -0.476 & \\
\hline CYNICISM & 0.347 & 0.315 & -0.093 & 0.191 & -0.469 & \\
\hline $\begin{array}{c}\text { LACK OF } \\
\text { EFFECTIVENESS }\end{array}$ & 0.380 & 0.345 & -0.102 & 0.209 & -0.514 & \\
\hline
\end{tabular}

Note: (D2) Problem-focused coping: F2. Seeking help and family advice; F5. Self-Instruction; F10. Positive reappraisal and firmness; F12. Communicating feelings and social support; F13. Seeking alternative reinforcement; (D1) Emotion-focused coping: F1. Avoidant distraction; F7. Reducing anxiety and avoidance; F8. Preparing for the worst; F9. Emotional venting and isolation; F11. Resigned acceptance.

Graphic representation of the structural model. The final model is graphically represented in Figure 2.

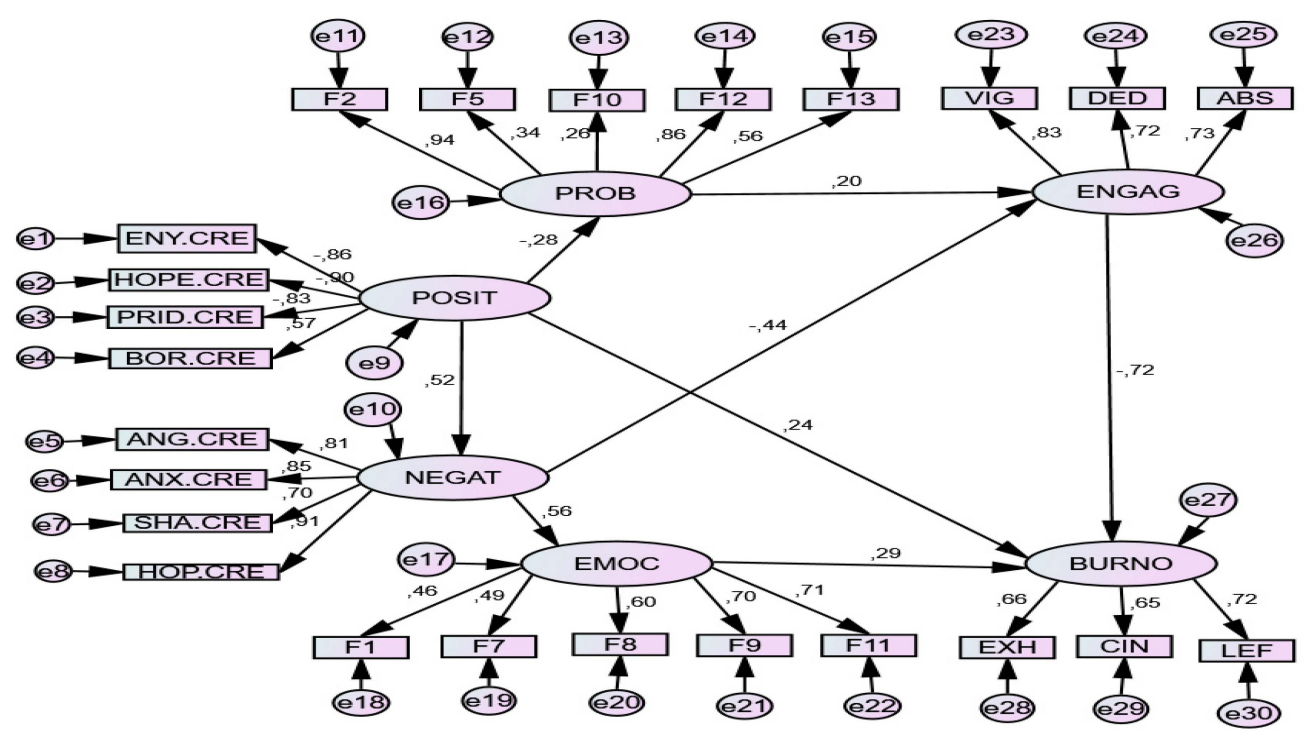

Figure 2. SEM model for Class Situation (Stress level 1). Note. POSIT = Positive Achievement Emotions (Enjoyment, Hope, Pride); NEGAT = Negative Achievement Emotions (Anger, Anxiety, Shame, Hopelessness, 
Boredom); PROB. Problem-focused strategies: F2. Seeking help and family advice; F5. Self-Instructions; F10. Positive reappraisal and firmness; F12. Comunicating feelings and social support; F13. Seeking alternative reinforcement; EMOC = Emotion-focused strategies F1. Avoidant distraction; F7. Reducing anxiety and avoidance; F8. Preparing for the worst; F9. Emotional venting and isolation; F11. Resigned acceptance; ENGAG = Engagement (Vigor, Dedication, Absorption); BURNO = Burnout (Exhaustion, Cynicism, Lack of Effectiveness).

\subsection{Study Situation (Stress Level 2)}

Standardized Direct Effects. In this situation, as in the previous, absence of positive emotions negatively $(-0.35)$ predicted problem-focused strategies and was a negative predictor or engagement (0.20); this absence also positively predicted negative emotions (0.52) and burnout (0.24). For their part, negative emotions more strongly predicted (0.56) emotion-focused strategies (0.56), which in turn were positive predictors $(0.26)$ of burnout; they were also negative predictors $(-0.44)$ of engagement. Consequently, burnout was predicted by an absence of positive emotions and the presence of negative emotions, in conjunction with emotion-focused strategies.

The results of pathway analysis (SEM) showed an acceptable model of the relationship between variables. The relationship parameters of both models are set out below. Two models were tested; the second obtained more consistent results and was taken as definitive. See Tables 6 and 7.

Table 6. Models of structural linear results of the variables.

\begin{tabular}{|c|c|c|c|c|c|c|c|c|}
\hline $\mathrm{Chi}^{2}$ & $p<$ & NFI & RFI & IFI & TLI & CFI & HOELT. & RMSEA \\
\hline $\begin{array}{l}\text { Model 4016.804 } \\
\text { (299-81): } 218\end{array}$ & 0.000 & 0.809 & 0.758 & 0.876 & 0.839 & 0.873 & 0.169 & 0.078 \\
\hline $\begin{array}{c}\text { Model 4257.872 } \\
(324-380): 224\end{array}$ & 0.000 & 0.906 & 0.927 & 0.907 & 0.940 & 0.908 & 0.204 & 0.080 \\
\hline
\end{tabular}

Table 7. Standardized Direct Effects (Default model): Study Situation.

\begin{tabular}{|c|c|c|c|c|c|c|}
\hline & POSIT & NEGAT & PROB & EMOT & ENGAGEMENT & BURNOUT \\
\hline NEGATIVE & 0.555 & & & & & \\
\hline PROBLEM & -0.301 & & & & & \\
\hline EMOTION & & 0.552 & & & & \\
\hline ENGAGEMENT & & -0.454 & 0.204 & & & \\
\hline BURNOUT & 0.268 & & & 0.269 & -0.705 & \\
\hline ENJOYMENT & -0.822 & & & & & \\
\hline HOPE & -0.889 & & & & & \\
\hline PRIDE & -0.836 & & & & & \\
\hline BOREDOM & 0.580 & & & & & \\
\hline ANGER & & 0.793 & & & & \\
\hline ANXIETY & & 0.820 & & & & \\
\hline SHAME & & 0.843 & & & & \\
\hline HOPELESSNESS & & 0.930 & & & & \\
\hline EEF2 & & & 0.937 & & & \\
\hline EEF5 & & & 0.338 & & & \\
\hline EECF10 & & & 0.259 & & & \\
\hline EECF12 & & & 0.863 & & & \\
\hline EECF13 & & & 0.563 & & & \\
\hline EECF1 & & & & 0.463 & & \\
\hline EEFC7 & & & & 0.489 & & \\
\hline EECF8 & & & & 0.605 & & \\
\hline EECF9 & & & & 0.696 & & \\
\hline EECF11 & & & & 0.712 & & \\
\hline
\end{tabular}


Table 7. Cont.

\begin{tabular}{|c|c|c|c|c|c|c|}
\hline & POSIT & NEGAT & PROB & EMOT & ENGAGEMENT & BURNOUT \\
\hline VIGOR & & & & & 0.838 & \\
\hline DEDICATION & & & & & 0.716 & \\
\hline ABSORPTION & & & & & 0.734 & \\
\hline EXHAUSTION & & & & & & 0.654 \\
\hline CYNICISM & & & & & & 0.644 \\
\hline LACK OF & & & & & & 0.728 \\
\hline EFFECTIVENESS & & & & & & $0.7 \angle 8$ \\
\hline
\end{tabular}

Note: (D2) Problem-focused coping: F2. Seeking help and family advice; F5. Self-Instruction; F10. Positive reappraisal and firmness; F12. Communicating feelings and social support; F13. Seeking alternative reinforcement; (D1) Emotion-focused coping: F1. Avoidant distraction; F7. Reducing anxiety and avoidance; F8. Preparing for the worst; F9. Emotional venting and isolation; F11. Resigned acceptance.

Standardized Indirect Effects. The model also contributed the existence of multiple indirect predictions among the variables. Complementing the direct effects, lack of positive emotions also had indirect predictive effects on emotion-focused coping (.306), negative effects on engagement (-0.314) and positive on burnout (.306). The absence of positive emotions positively predicted numerous negative emotions and emotion-focused coping strategies. Negative emotions also predicted coping strategies focused on emotion. Coping strategies focused on the problem positively predicted engagement, while emotion-focused strategies predicted burnout. See Table 8 and Figure 3.

Table 8. Standardized Indirect Effects (Default model). Learning Situation.

\begin{tabular}{|c|c|c|c|c|c|c|}
\hline & POSIT & NEGAT & PROB & EMOT & ENGAGEMENT & BURNOUT \\
\hline \multicolumn{7}{|l|}{ NEGATIVE } \\
\hline \multicolumn{7}{|l|}{ PROBLEM } \\
\hline EMOTION & 0.306 & & & & & \\
\hline ENGAGEMENT & -0.134 & & & & & \\
\hline BURNOUT & 0.306 & 0.469 & -0.144 & & & \\
\hline \multicolumn{7}{|l|}{ ENJOYMENT } \\
\hline \multicolumn{7}{|l|}{ HOPE } \\
\hline \multicolumn{7}{|l|}{ PRIDE } \\
\hline \multicolumn{7}{|l|}{ BOREDOM } \\
\hline ANGER & 0.440 & & & & & \\
\hline ANXIETY & 0.455 & & & & & \\
\hline SHAME & 0.468 & & & & & \\
\hline HOPELESSNESS & 0.516 & & & & & \\
\hline EEF2 & -0.282 & & & & & \\
\hline EEF5 & -0.102 & & & & & \\
\hline EECF10 & -0.078 & & & & & \\
\hline EECF12 & -0.260 & & & & & \\
\hline EECF13 & -0.170 & & & & & \\
\hline EECF1 & 0.142 & & & & & \\
\hline EEFC7 & 0.150 & & & & & \\
\hline EECF8 & 0.185 & & & & & \\
\hline EECF9 & 0.213 & & & & & \\
\hline EECF11 & 0.218 & & & & & \\
\hline VIGOR & -0.263 & -0.381 & 0.171 & & & \\
\hline DEDICATION & -0.225 & -0.325 & 0.146 & & & \\
\hline ABSORPTION & -0.230 & -0.334 & 0.150 & & & \\
\hline EXHAUSTION & 0.373 & 0.306 & -0.094 & 0.176 & -0.461 & \\
\hline CYNICISM & 0.368 & 0.302 & -0.093 & 0.173 & -0.454 & \\
\hline $\begin{array}{c}\text { LACK OF } \\
\text { EFFECTIVENESS }\end{array}$ & 0.416 & 0.341 & -0.105 & 0.196 & -0.513 & \\
\hline
\end{tabular}

Note: (D2) Problem-focused coping: F2. Seeking help and family advice; F5. Self-Instruction; F10. Positive reappraisal and firmness; F12. Communicating feelings and social support; F13. Seeking alternative reinforcement; (D1) Emotion-focused coping: F1. Avoidant distraction; F7. Reducing anxiety and avoidance; F8. Preparing for the worst; F9. Emotional venting and isolation; F11. Resigned acceptance. 


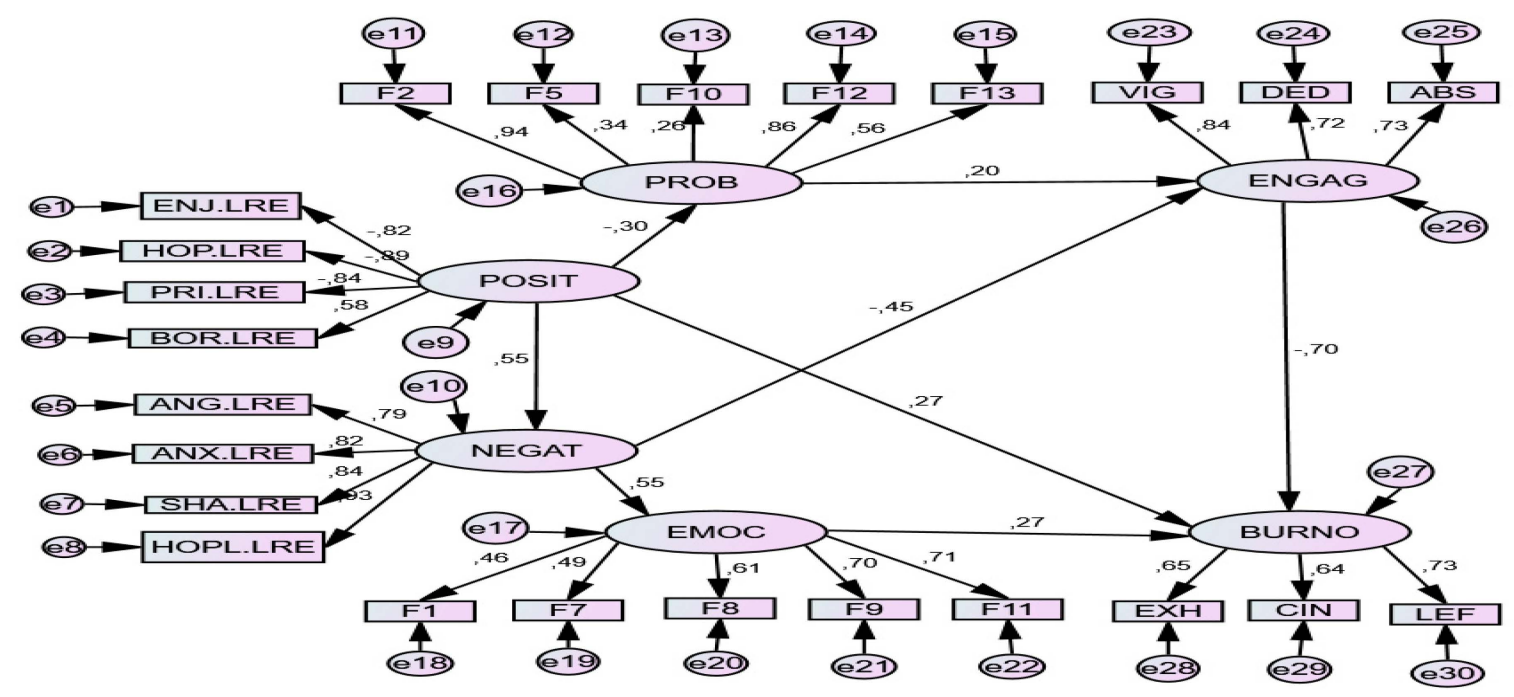

Figure 3. SEM model for Study Situation (Stress level 2). Note. POSIT = Positive Achievement Emotions (Enjoyment, Hope, Pride); NEGAT = Negative Achievement Emotions (Anger, Anxiety, Shame, Hopelessness, Boredom); PROB. Problem-focused strategies: F2. Seeking help and family advice; F5. Self-Instructions; F10. Positive reappraisal and firmness; F12. Comunicating feelings and social support; F13. Seeking alternative reinforcement; EMOC = Emotion-focused strategies F1. Avoidant distraction; F7. Reducing anxiety and avoidance; F8. Preparing for the worst; F9. Emotional venting and isolation; F11. Resigned acceptance; ENGAG = Engagement (Vigor, Dedication, Absorption); BURNO = Burnout (Exhaustion, Cynicism, Lack of Effectiveness).

\subsection{Test Situation (Stress Level 3)}

The results of pathway analysis (SEM) showed an acceptable model of the relationships between variables. The relationship parameters of both models are set out below. Two models were tested; the second obtained more consistent results and was taken as definitive. See Table 9 and Figure 4.

Table 9. Models of structural linear results of the variables.

\begin{tabular}{ccccccccc}
\hline $\mathbf{C h i}^{\mathbf{2}}$ FG & $p<$ & NFI & RFI & IFI & TLI & CFI & HOELT. & RMSEA \\
\hline $\begin{array}{c}\text { Model 2544.602 } \\
(299-81): ~ 218\end{array}$ & 0.000 & 0.823 & 0.855 & 0.816 & 0.809 & 0.856 & 0.169 & 0.078 \\
\hline $\begin{array}{c}\text { Model 3900.927 } \\
(324-380): 224\end{array}$ & 0.000 & 0.905 & 0.937 & 0.918 & 0.925 & 0.917 & 0.203 & 0.080 \\
\hline
\end{tabular}

Standardized Direct Effects. In this situation, unlike the two previous ones, the presence of positive emotions positively predicted $(0.21)$ problem-focused strategies, which in turn were positive predictors of engagement ( 0.20$)$; they were also negative predictors of negative emotions $(-0.52)$ and burnout $(-0.24)$. For their part, negative emotions more strongly predicted (0.56) emotion-focused strategies $(0.56)$, which in turn were predictors $(0.26)$ of burnout; they were also negative predictors $(-0.44)$ of engagement. Consequently, engagement was predicted by positive emotions and problem-focused strategies, while burnout was predicted by negative emotions and emotion-focused strategies. See Table 10.

Standardized Indirect Effects. The model also revealed multiple indirect predictions among the variables. Complementing the direct effects, positive emotions also had indirect predictive effects on emotion-focused coping (-0.236), positive effects on engagement ( 0.227$)$ and negative on burnout $(-0.246)$. Positive emotions negatively predicted numerous negative emotions and emotion-focused coping strategies. Negative emotions also predicted coping strategies focused on emotion. Problem-focused coping strategies positively predicted engagement, while emotion-focused strategies predicted burnout. See Table 11. 


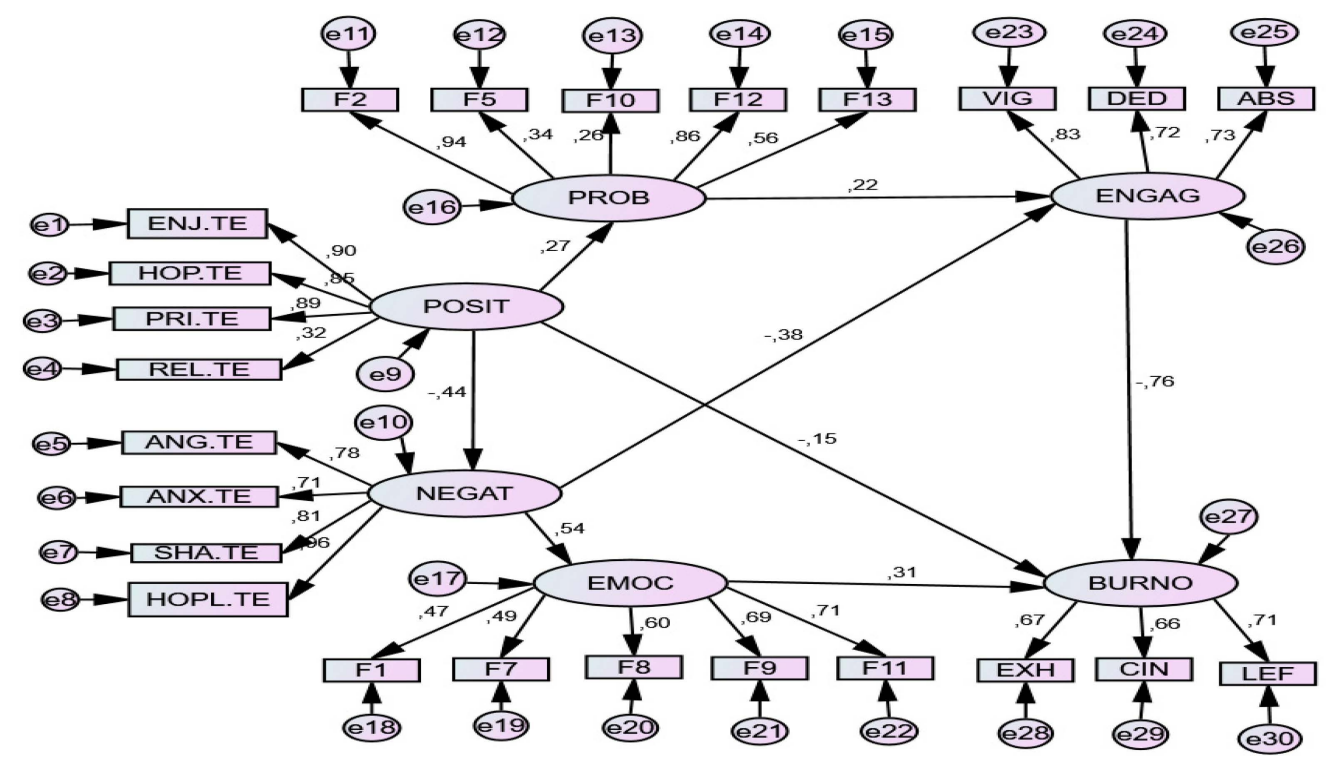

Figure 4. SEM model for Test Situation (Stress level 3). Note. POSIT = Positive Achievement Emotions (Enjoyment, Hope, Pride); NEGAT = Negative Achievement Emotions (Anger, Anxiety, Shame, Hopelessness, Boredom); PROB. Problem-focused strategies: F2. Seeking help and family advice; F5. Self-Instructions; F10. Positive reappraisal and firmness; F12. Comunicating feelings and social support; F13. Seeking alternative reinforcement; EMOC = Emotion-focused strategies F1. Avoidant distraction; F7. Reducing anxiety and avoidance; F8. Preparing for the worst; F9. Emotional venting and isolation; F11. Resigned acceptance; ENGAG = Engagement (Vigor, Dedication, Absorption); BURNO = Burnout (Exhaustion, Cynicism, Lack of Effectiveness).

Table 10. Standardized Direct Effects (Default model): Test Situation.

\begin{tabular}{|c|c|c|c|c|c|c|}
\hline & POSIT & NEGAT & PROB & EMOT & ENGAGEMENT & BURNOUT \\
\hline NEGATIVE & -0.439 & & & & & \\
\hline PROBLEM & 0.273 & & & & & \\
\hline EMOTION & & 0.538 & & & & \\
\hline ENGAGEMENT & & -0.378 & 0.225 & & & \\
\hline BURNOUT & -0.151 & & & 0.313 & -0.757 & \\
\hline ENJOYMENT & 0.903 & & & & & \\
\hline HOPE & 0.850 & & & & & \\
\hline PRIDE & 0.891 & & & & & \\
\hline BOREDOM & 0.322 & & & & & \\
\hline ANGER & & 0.784 & & & & \\
\hline ANXIETY & & 0.707 & & & & \\
\hline SHAME & & 0.807 & & & & \\
\hline HOPELESSNESS & & 0.956 & & & & \\
\hline EEF2 & & & 0.938 & & & \\
\hline EEF5 & & & 0.337 & & & \\
\hline EECF10 & & & 0.258 & & & \\
\hline EECF12 & & & 0.863 & & & \\
\hline EECF13 & & & 0.564 & & & \\
\hline EECF1 & & & & 0.466 & & \\
\hline EEFC7 & & & & 0.491 & & \\
\hline EECF8 & & & & 0.604 & & \\
\hline EECF9 & & & & 0.691 & & \\
\hline EECF11 & & & & 0.712 & & \\
\hline
\end{tabular}


Table 10. Cont.

\begin{tabular}{|c|c|c|c|c|c|c|}
\hline & POSIT & NEGAT & PROB & EMOT & ENGAGEMENT & BURNOUT \\
\hline VIGOR & & & & & 0.831 & \\
\hline DEDICATION & & & & & 0.721 & \\
\hline ABSORPTION & & & & & 0.732 & \\
\hline EXHAUSTION & & & & & & 0.668 \\
\hline CYNICISM & & & & & & 0.657 \\
\hline LACK OF & & & & & & 0.714 \\
\hline
\end{tabular}

Note: (D2) Problem-focused coping: F2. Seeking help and family advice; F5. Self-Instruction; F10. Positive reappraisal and firmness; F12. Communicating feelings and social support; F13. Seeking alternative reinforcement; (D1) Emotion-focused coping: F1. Avoidant distraction; F7. Reducing anxiety and avoidance; F8. Preparing for the worst; F9. Emotional venting and isolation; F11. Resigned acceptance.

Table 11. Standardized Indirect Effects (Default model). Test Situation.

\begin{tabular}{ccccccc}
\hline & POSIT & NEGAT & PROB & EMOT & ENGAGEMENT & BURNOUT \\
\hline NEGATIVE & & & & & & \\
PROBLEM & & & & & \\
EMOTION & -0.236 & & & & \\
ENGAGEMENT & 0.227 & & & & \\
BURNOUT & -0.246 & 0.454 & -0.170 & & \\
\hline ENJOYMENT & & & & & \\
HOPE & & & & & \\
PRIDE & & & & & \\
BOREDOM & & & & & \\
\hline ANGER & -0.334 & & & & \\
ANXIETY & -0.310 & & & & \\
SHAME & -0.354 & & & & \\
HOPELESSNESS & -0.420 & & & & \\
\hline EEF2 & 0.257 & & & & \\
EEF5 & 0.092 & & & & \\
EECF10 & 0.070 & & & & \\
EECF12 & 0.236 & & & & \\
EECF13 & 0.154 & & & & \\
\hline EECF1 & -0.110 & 0.251 & & & \\
EEFC7 & -0.116 & 0.264 & & & \\
EECF8 & -0.143 & 0.325 & & & \\
EECF9 & -0.163 & 0.372 & & & \\
EECF11 & -0.168 & 0.383 & & & \\
VIGOR & 0.166 & -0.314 & 0.187 & & \\
DEDICATION & 0.164 & -0.273 & 0.162 & & \\
ABSORPTION & 0.189 & -0.276 & 0.164 & & \\
\hline EXHAUSTION & -0.265 & 0.304 & -0.170 & & \\
CYNICISM & -0.281 & 0.298 & -0.114 & & \\
LACK OF & -0.263 & 0.324 & & & \\
EFFECTIVENESS & & & & \\
\hline
\end{tabular}

Note: (D2) Problem-focused coping: F2. Seeking help and family advice; F5. Self-Instruction; F10. Positive reappraisal and firmness; F12. Communicating feelings and social support; F13. Seeking alternative reinforcement; (D1) Emotion-focused coping: F1. Avoidant distraction; F7. Reducing anxiety and avoidance; F8. Preparing for the worst;

F9. Emotional venting and isolation; F11. resignedacceptance.

\section{Discussion}

The objective of this investigation was to contribute new evidence to verify whether positive versus negative emotions predicted problem- or emotion-focused coping strategies, and ultimately, a state of engagement versus burnout, in the context of perfectionism research. This intriguing objective took the shape of two hypotheses which were in large measure validated.

Hypothesis 1 -positive emotions would predispose the use of problem-focused coping strategies and an attitude or emotional state of engagement when learning- was confirmed in the all situation by 
linear regression analyses and structural multiple prediction analyses (in the exam situation). Positive emotions consistently predicted problem-focused coping strategies (F5: Self-instructions; and F10: Positive reappraisal and firmness) and engagement. Regarding Hypothesis 2 -negative emotions were found to predict unhealthful coping strategies (F9: Emotional venting and isolation), and an ultimate state of burnout-, was confirmed in all three situations by linear regression analyses and structural multiple prediction analyses.

These results are consistent with prior evidence that has established associations between positive emotionality and self-regulation, and between negative emotionality and a lack of selfregulation [47-66]. Results presented in this research study also reveal the specific strategic coping behaviors that are associated with students' emotions and their ultimate emotional state of engagement vs. burnout, suggesting that coping strategies are a meta-emotional variable, or, as their name implies, a behavioral strategy, adjusted or maladjusted, for managing emotions. Although the revised model by Lazarus and Folkman [36] already notes that the use of both types of strategies can be adaptive in daily life, the present study suggests a specific explanatory mechanism for the two types: (1) positive emotions, typical of the absence of stress, are most likely to result in the use of problem-focused strategies, with less focus on emotions, which in turn will give rise to a state of engagement; (2) negative emotions, typical of stressful states, would result in a preference for emotion-focused strategies, which ultimately would lead to burnout, and (3) the absence of positive emotions would also lead to burnout. These results seem to suggest that coping strategies, besides acting as a mediating variable, also act directly, along with emotions, in producing one state or another. For this reason, coping strategies could be considered a more precise behavioral mechanism in engagement vs. burnout. It seems plausible that the psychological wear and tear of negative achievement emotions (or the absence of positive ones), together with the strategic effort involved in managing them through extensive use of emotion-focused strategies, can result in burnout.

When considering each academic situation, however, the proposed predictive structural model (SEM) was not the exact model found in the classroom and study situations, due to the negative weight of positive emotions. That is, a lack of positive emotionality -associated with the presence of negative emotionality-produced a preference for using emotion-focused strategies to cope with the emotional state of burnout during class and during study time. This result is highly interesting, because it suggests that the teaching process is involved. Although the teaching process is not the object of this analysis, recent evidence shows that teaching does play its role, and university students' emotional state is the combined product of students' personal characteristics and contextual characteristics $[66,67]$. The proposed model, however, was fulfilled in the testing situation. These differential results would indicate that achievement emotions operate differently in the three situations to which university students are exposed, as analyzed here. The causes of these differences could be the object of future research. The stress factors implicit to certain teaching processes would probably be key to understanding these results (de la Fuente, et al., 2020). In any event, the analysis of achievement emotions has added factors not traditionally considered onto the agenda of university research $[68,69]$.

\section{Limitations and Future Research}

This evidence leads us to ask: why do the university students assessed have such little positive emotionality (enjoyment, confidence and pride) in classroom and study situations, and why is it that positive emotionality is activated in a testing situation? Is the problem with teaching or with learning? Does it depend on personality or gender variables? These factors have not been the object of study here, and therefore represent a study limitation. Our hypotheses have been partially supported by the results presented here. Future studies should follow the direction or trend established here with more precise methodology. The role of certain variables should be clarified, especially those referring to the role of the teaching process, in its interaction with the personal variables analyzed in the present study [70]. Despite these limitations, this study has been able to connect variables that had not been sufficiently analyzed to date, namely, achievement emotions (affective variables of the learning process), coping 
strategies (meta-emotional variables of the learning process) and emotional state (motivational variable of learning).

The limited number of degree programs represented in our participants, and the total number of participating students, also represent important limitations. In order to make generalizable inferences, future studies must expand the number of degree programs represented and the international profile of participating students. Taking all this into account, the results found here are meaningful but must be taken with caution.

Another limitation pertains to the use of a linear predictive methodology. An associative type methodology does not allow us to infer causality or interdependence, only probability prediction. Future research should clarify the papel of age and gender in the relationships found. Additionally, future research should explicitly analyze this plausible, hypothesized relationship, not explicitly verified in the present research report. This line of analysis could help us better understand the differences between types of perfectionism. Previous evidence has generally reported a negative association between perfectionistic strivings and burnout symptoms such as exhaustion, cynicism, and inefficacy. On the other hand, some researchers [71] found the opposite effect, reporting that perfectionistic strivings correlated positively to exhaustion and cynicism. Perfectionistic concerns involve a persistent, negative reaction to imperfections, thereby increasing fatigue [72], and burnout [73]. One possible reason for this is that negative emotions and the effort required to manage them involve the use of many emotional and cognitive resources, which in turn leaves fewer resources for pursuing problem-focused strategies, hence resulting in ego-depletion and burnout.

\section{Implications and Applicability}

Understanding how achievement emotions operate in university students is highly relevant, since these emotions have a positive or negative effect on students' performance and their use of available personal resources. If a lack of positive emotionality and presence of negative emotionality mean that many behavioral resources must be applied, it is reasonable to think that fewer resources are left for task execution. Furthermore, burnout and lack of engagement will follow in the medium term, predisposing dropout or poor achievement [10].

A first implication for educational psychology would be the implementation of preventive programs that assess these variables in university students and determine what aspects stem from personal factors as opposed to contextual factors. With this knowledge, formative intervention processes could be designed for students and teachers, for the purpose of improving teaching and learning processes at the university [74], and to address the personal factor of perfectionism.

Second, an understanding of the relationships presented here is essential to assessment and intervention in clinical and health psychology. These predictive models can be the foundation for specific strategies for treating the stress that characterizes university achievement. Achievement emotions, as well as other factors and symptoms of stress and burnout, should be accurately assessed, in the line of recent proposals [75]. From a Clinical Psychology approach, not only should individual variables be considered, but also their interaction with possibly relevant contextual variables, particularly in the academic setting. Among the contextual factors, common aspects should be identified, as well as aspects that explain the differential impact of achievement emotions in the three situations of classroom, study time and testing, as shown in this model [15]. Some of the factors that should be clinically evaluated are emotional self-regulation, certain personality variables (emotional stability, resilience, security, control), psychopathology, coping styles, emotional expression modes and social skills. On the other hand, interventions focused on modifying emotional regulation strategies could be designed to address aspects like activation or attention, or offer specific training to enhance performance. Such interventions could have an individual, group or online format, the latter showing demonstrated effectiveness in recent years $[46,74]$. 


\section{Conclusions}

Findings from this empirical study reveal that achievement emotions in fact have a linear, predictive relationship with the type of coping strategies applied, and ultimately, with the resulting motivational state. This linear relationship, however, seems to be influenced by the specific situation and by interaction with this situation, as shown in recent research [76,77]. Consequently, we must continue to investigate how the person $x$ situation interaction is produced, in order to reach a better understanding of emotions during academic learning at university. The primary, secondary and tertiary prevention strategies that we use to provide psychological support to university students depend on this understanding, especially in cases where students are characterized by a maladjusted pattern of perfectionism.

Author Contributions: Conceptualization, J.d.1.F. and F.L.-R.; methodology, J.d.1.F. and C.L.-S.; software, J.d.1.F.; validation, C.M.-M. and I.A.; formal analysis, F.L.-R. and E.A.; investigation, J.d.l.F.; resources, I.A. and R.M.-L.; writing-original draft preparation, J.d.l.F. and F.L.-R.; writing-review and editing, C.L.-S. and E.A.; project administration, J.d.l.F.; funding acquisition, J.d.l.F. All authors have read and agreed to the published version of the manuscript.

Funding: This research was funded by R\&D Project PGC2018-094672-B-I00 (Ministry of Science and Education, Spain), and the European Social Fund; UAL18-SEJ-DO31-A-FEDER (University of Almería, Spain), and the European Social Fund.

Conflicts of Interest: The authors declare no conflict of interest. The funders had no role in the design of the study; in the collection, analyses, or interpretation of data; in the writing of the manuscript, or in the decision to publish the results.

\section{References}

1. Duffy, M.C.; Lajoie, S.P.; Pekrun, R.; Lachapelle, K. Emotions in medical education: Examining the validity of the Medical Emotion Scale (MES) across authentic medical learning environments. Learn. Instr. 2018. [CrossRef]

2. Gentsch, K.; Loderer, K.; Soriano, C.; Fontaine, J.R.; Eid, M.; Pekrun, R.; Scherer, K.R. Effects of achievement contexts on the meaning structure of emotion words. Cogn. Emot. 2018, 32, 379-388. [CrossRef] [PubMed]

3. Goetz, T.; Frenzel, A.; Hall, N.C.; Nett, U.E.; Pekrun, R.; Lipnevich, A.A. Types of boredom: An experience sampling approach. Motiv. Emot. 2014, 38, 401-419. [CrossRef]

4. Harley, J.M.; Pekrun, R.; Taxer, J.L.; Gross, J.J. Emotion Regulation in Achievement Situations: An Integrated Model. Educ. Psychol. 2019, 54, 106-126. [CrossRef]

5. Linnenbrink-Garcia, L.; Pekrun, R. Students' emotions and academic engagement [Special issue]. Contemp. Educ. Psychol. 2011, 36, 1-3. [CrossRef]

6. Loderer, K.; Pekrun, R.; Lester, J.C. Beyond cold technology: A meta-analytic review of research on emotions in technology-based learning environments. Learn. Instr. 2018. [CrossRef]

7. Lüftenegger, M.; Klug, J.; Harrer, K.; Langer, M.; Spiel, C.; Schober, B. Students' Achievement Goals, Learning-Related Emotions and Academic Achievement. Front. Psychol. 2016, 7, 603. [CrossRef]

8. D'Mello, S. A selective meta-analysis on the relative incidence of discrete affective states during learning with technology. J. Educ. Psychol. 2013, 105, 1082-1099. [CrossRef]

9. Pidgeon, A.M.; Pittner, L. Examining the Differences Between University Students' Levels of Resilience on Mindfulness, Psychological Distress and Coping Strategies. Eur. Sci. J. 2017, 103-117. [CrossRef]

10. Palmer, A.; Rodger, S. Mindfulness, stress and coping among university students. Can. J. Couns. 2009, 43, 198-212.

11. Sadeghi Bahmani, D.; Faraji, P.; Faraji, R.; Lang, U.E.; Holsboer-Trachsler, E.; Brand, S. Is emotional functioning related to academic achievement among university students? Results from a cross-sectional Iranian sample. Rev. Bras. Psiquiatr. 2018, 40, 290-295. [CrossRef] [PubMed]

12. Mainhard, T.; Oudman, S.; Hornstra, L.; Bosker, R.J.; Goetz, T. Student emotions in class: The relative importance of teachers and their interpersonal relations with students. Learn. Instr. 2018, 53, 109-119. [CrossRef]

13. Pekrun, R.; Goetz, T.; Titz, W.; Perry, R.P. Academic emotions in students' self-regulated learning and achievement: A program of qualitative and quantitative research. Educ. Psychol. 2002, 37, 91-105. [CrossRef] 
14. Shaw, M.P.; Peart, D.J.; William, O.J. Perceived stress in university students studying in a further education college. Res. Post-Compuls. Educ. 2017, 22, 442-452. [CrossRef]

15. de la Fuente, J.; Amate, J.; González-Torres, M.C.; Artuch, R.; García-Torrecillas, J.M.; Fadda, S. Effects of Levels of Self-Regulation and Regulatory Teaching on Strategies for Coping with Academic Stress in Undergraduate Students. Front. Psychol. 2020, 11, 22. [CrossRef] [PubMed]

16. McKinley, N.; McCain, R.S.; Convie, L.; Clarke, M.; Dempster, M.; Campbell, W.J.; Kirk, S.J. Resilience, burnout and coping mechanisms in UK doctors: A cross-sectional study. BMJ Open 2020, 10, e031765. [CrossRef]

17. Frost, R.O.; Marten, P.; Lahart, C.; Rosenblate, R. The dimensions of perfectionism. Cogn. Ther. Res. 1990, 14, 449-468. [CrossRef]

18. Dixon, F.A.; Lapsley, D.K.; Hanchon, T.A. An empirical typology of perfectionism in gifted adolescents. Gift. Child Q. 2004, 48, 95-106. [CrossRef]

19. Gaudreau, P.; Franche, V.; Gareau, A. A latent mediated moderation of perfectionism, motivation, and academic satisfaction: Advancing the $2 \times 2$ model of perfectionism through substantive-methodological synergy. J. Psychoeduc. Assess. 2016, 34, 688-701. [CrossRef]

20. Damian, L.E.; Stoeber, J.; Negru, O.; Băban, A. Perfectionism and achievement goal orientations in adolescent school students. Psychol. Sch. 2014, 51, 960-971. [CrossRef]

21. Franche, V.; Gaudreau, P.; Miranda, D. The $2 \times 2$ model of perfectionism: A comparison across Asian Canadians and European Canadians. J. Couns. Psychol. 2012, 59, 567. [CrossRef] [PubMed]

22. Cumming, J.; Duda, J.L. Profiles of perfectionism, body-related concerns, and indicators of psychological health in vocational dance students: An investigation of the $2 \times 2$ model of perfectionism. Psychol. Sport Exerc. 2012, 13, 729-738. [CrossRef]

23. Mackinnon, S.P.; Sherry, S.B. Perfectionistic self-presentation mediates the relationship between perfectionistic concerns and subjective well-being: A three-wave longitudinal study. Personal. Individ. Differ. 2012, 53, 22-28. [CrossRef]

24. Stoeber, J.; Damian, L.E. Perfectionism in employees: Work engagement, workaholism, and burnout. In Perfectionism, Health, and Well-Being; Sirois, F.M., Molnar, D.S., Eds.; Springer: Cham, Switzerland, 2016; pp. 265-283. [CrossRef]

25. Pekrun, R. The control-value theory of achievement emotions: Assumptions, corollaries, and implications for educational research and practice. Educ. Psychol. Rev. 2006, 18, 315-341. [CrossRef]

26. Pekrun, R.; Frenzel, A.C.; Goetz, T.; Perry, R.P. The control-value theory of achievement emotions: An integrative approach to emotions in education. In Emotion in Education; Schurtz, P.A., Pekrun, R., Eds.; Academic Press: Amsterdan, The Netherlands, 2007; pp. 13-36.

27. Goetz, T.; Frenzel, A.C.; Pekrun, R. Regulation von Langeweile im Unterricht. Was Schülerinnen und Schüler bei der "Windstille der Seele" (nicht) tun [Regulation of boredom during classroom instruction]. Unterrichtswissenschaft 2007, 35, 312-333.

28. Frenzel, A.C.; Becker-Kurz, B.; Pekrun, R.; Goetz, T.; Lüdtke, O. Emotion transmission in the classroom revisited: A reciprocal effects model of teacher and student enjoyment. J. Educ. Psychol. 2018, 110, 628-639. [CrossRef]

29. Pekrun, R.; Goetz, T.; Perry, R.P. Academic Emotions Questionnaire (AEQ); User's manual; Department of Psychology, University of Munich: Munich, Germany, 2005; Available online: https:/es.scribd.com/doc/ 217451779/2005-AEQ-Manual (accessed on 20 March 2020).

30. Pekrun, R.; Stephens, E.J. Academic emotions. In APA Educational Psychology Handbook, Individual Differences and Cultural and Contextual Factors; Harris, K.R., Ed.; American Psychological Association: Washington, DC, USA, 2012; Volume 2, pp. 3-31.

31. Riemer, V.; Schrader, C. Mental Model Development in Multimedia Learning: Interrelated Effects of Emotions and Self-Monitoring. Front. Psychol. 2019, 10, 899. [CrossRef]

32. Putwain, D.W. An examination of the self-referent executive processing model of test anxiety: Control, emotional regulation, self-handicapping, and examination performance. Eur. J. Psychol. Educ. 2019, 1-18. [CrossRef]

33. Kamijo, N.; Yukawa, S. The Role of Rumination and Negative Affect in Meaning Making Following Stressful Experiences in a Japanese Sample. Front. Psychol. 2018, 9, 2404. [CrossRef] 
34. Vierhaus, M.; Lohaus, A.; Wild, E. The development of achievement emotions and coping/emotion regulation from primary to secondary school. Learn. Instr. 2016, 42, 12-21. [CrossRef]

35. de la Fuente, J. Competence for Studying, Learning and Performance under Stress: Self-help Guide for University Students, Graduates and Professional Examination Candidades; e-Publishing Series I+ D+ I; Education \& Psychology I+ D+ I: Almería, Spain, 2015.

36. Lazarus, R.S.; Folkman, S. Stress, Appraisal and Coping; Springer Publishing Company Inc.: New York, NY, USA, 1984.

37. Lazarus, R.S. Psychological Stress and the Coping Process; McGraw-Hill: New York, NY, USA, 1966.

38. Folkman, S. The case for positives emotions in the stress process. Anxiety Stress Coping 2008, 21, 3-14. [CrossRef] [PubMed]

39. Folkman, S. Stress, health, and coping: Synthesis, commentary, and future directions. In The Oxford Handbook of Stress, Health, and Coping; Folkman, S., Ed.; Oxford University Press: Oxford, UK, 2011; pp. 453-462.

40. Kirby, R.; Shakespeare-Finch, J.; Palk, G. Adaptive and maladaptive coping strategies predict posttrauma outcomes in ambulance personnel. Traumatology 2011, 17, 25-34. [CrossRef]

41. Jenkins, S.R. Coping and social support among emergency dispatchers: Hurricane Andrew. J. Soc. Behav. Personal. 1997, 12, 201-216.

42. Littleton, H.; Axsom, D.; Grills-Taquechel, A.E. Longitudinal evaluation of the relationship between maladaptive trauma coping and distress: Examination following the mass shooting at Virginia Tech. Anxiety Stress Coping 2011, 24, 273-290. [CrossRef] [PubMed]

43. Tada, A. The Associations among Psychological Distress, Coping Style, and Health Habits in Japanese Nursing Students: A Cross-Sectional Study. Int. J. Env. Res. Public Health 2017, 14, 1434. [CrossRef]

44. Bhullar, N.; Hine, D.W.; Phillips, W.J. Profiles of psychological well-being in a simple of Australian university students. Int. J. Psychol. 2014, 49, 288-294. [CrossRef]

45. Freire, C.; Ferradás, M.M.; Valle, A.; Núñez, J.C.; Vallejo, G. Profiles of Psychological Well-being and Coping Strategies among University Students. Front. Psychol. 2016, 7, 1554. [CrossRef]

46. Freire, C.; Ferradás, M.M.; Núñez, J.C.; Valle, A.; Vallejo, G. Eudaimonic Well-Being and Coping with Stress in University Students: The Mediating/Moderating Role of Self-Efficacy. Int. J. Environ. Res. Public Health 2018, 16, 48. [CrossRef]

47. de la Fuente, J.; García-Torrecillas, J.M.; Rodríguez-Vargas, S. The relationships between Coping Strategies, test anxiety and Burnout-Engagement behavior in university undergraduates. In Coping Strategies and Health 2015; Bachman, M., Ed.; Nova Science Publisher: New York, NY, USA, 2015; pp. 27-41.

48. Maslach, C.; Jackson, S.E. The measurement of experienced burnout. J. Occup. Behav. 1981, 2, 99-113. [CrossRef]

49. Maslach, C.; Leiter, M.P. The Truth about Burnout: How Organizations Cause Personal Stress and What to do about It; Jossey-Bass: San Francisco, CA, USA, 1997.

50. Leiter, M.P.; Marlach, C. Burnout and engagement: Contributions to a new visión. Burn. Res. 2017, 5, 55-57. [CrossRef]

51. Leiter, M.P.; Marlach, C. Latent burnout profiles: A new approach to understanding the burnout experience. Burn. Res. 2017, 3, 89-100. [CrossRef]

52. Ocampo, A.C.G.; Wang, L.; Kiazad, K.; Restubog, S.L.D.; Ashkanasy, N.M. The relentless pursuit of perfectionism: A review of perfectionism in the workplace and an agenda for future research. J. Organ. Behav. 2020, 41, 144-168. [CrossRef]

53. Burr, J.; Dallaghan, J.L.B. The Relationship of Emotions and Burnout to Medical Students' Academic Performance. Teach. Learn. Med. 2019. [CrossRef] [PubMed]

54. Watson, D.; Clark, L.A. On traits and temperament: General and specific factors of emotional experience and their relation to the five-factor model. J. Personal. 1992, 60, 441-476. [CrossRef] [PubMed]

55. Paoloni, P. The Achievement Emotions Questionnaire, AEQ: Class-Related Emotions (Spanish Version); CONICET; University of Río Quarto: Buenos Aires, Argentina, 2014.

56. de la Fuente, J. The Achievement Emotions Questionnaire, AEQ: Learning and Test-Related Emotions (Spanish Version); University of Almería: Almería, Spain, 2015.

57. de la Fuente, J. Short EEC Scal; University of Almería: Almería, Spain, 2014.

58. Chorot, P.; Sandín, B. Escalas de Estrategias de Coping [Scales of Coping Strategies]; UNED: Madrid, Spain, 1987. 
59. Shaufeli, W.R.; Martínez, I.S.; Marqués, A.; Salanova, S.; Bakker, A.B. Burnout and engagement in university students. A Cross-National Study. J. Cross-Cultural Psychol. 2002, 33, 464-481. [CrossRef]

60. Maslach, C.; Jackson, S.E.; Leiter, M.P.; Schaufeli, W.B.; Schwab, R.L. Maslach burnout inventory; Consulting Psychologists Press: Palo Alto, CA, USA, 1986; Volume 21, pp. 3463-3464.

61. de la Fuente, J.; López, M.; Zapata, L.; Sollinas, G.; Fadda, S. Improving mental Health trough and online self-assessment and self-help e-Utility in university Students. In Progress in Education; Nata, R.V., Ed.; Nova Publisher: New York, NY, USA, 2015; Volume 33, pp. 63-74.

62. McDonald, R.P.; Marsh, H.W. Choosing a multivariate model: Noncentrality and goodness of fit. Psychol. Bull. 1990, 107, 247. [CrossRef]

63. Jöreskog, K.G.; Sörbom, D. LISREL 8: Structural equation modeling with the SIMPLIS command language; Scientific Software International: Chicago, IL, USA, 1993.

64. Keith, T.Z. Multiple regression and beyond: An introduction to multiple regression and structural equation modeling; Routledge: London, UK, 2014.

65. Kenny, D. Mediation: The indirect effect [PowerPoint slides]. 2014. Available online: http://davidakenny.net/ $\mathrm{cm} /$ mediate.htm (accessed on 20 March 2020).

66. de la Fuente, J.; Martínez-Vicente, J.M.; Peralta-Sánchez, F.J.; Garzón-Umerenkova, A.; Vera, M.M.; Paoloni, P. Applying the SRL vs ERL Theory to the knowledge of Achievement Emotions in Undergraduate University Students. Front. Psychol. 2019, 10, 2070. [CrossRef] [PubMed]

67. de la Fuente, J.; Sander, P.; Martínez-Vicente, J.M.; Vera, M.M.; Garzón, A.; Fadda, S. Combined Effect of Levels in Personal Self-Regulation and Regulatory Teaching on Meta-Cognitive, on Meta-Motivational, and on Academic Achievement Variables in Undergraduate Students. Front. Psychol. 2017, 8, 232. [CrossRef] [PubMed]

68. Respondeka, L.; Seuferta, T.; Nettb, U.E. Adding previous experiences to the person-situation debate of achievement emotions. Contemp. Educ. Psychol. 2019, 58, 19-32. [CrossRef]

69. Tze, V.C.; Klassen, R.M.; Daniels, L.M. Patterns of boredom and its relationship with perceived autonomy support and engagement. Contemp. Educ. Psychol. 2014, 39, 175-187. [CrossRef]

70. Lekwa, A.J.; Reddy, L.A.; Shernoff, E.S. Measuring Teacher Practices and Student Academic Engagement: A Convergent Validity Study. Sch. Psychol. Q. 2018. [CrossRef] [PubMed]

71. Caliskan, S.C.; Arikan, S.C.; Saatchi, E.Y. SMEs context of Turkey from the relational perspective of members' perfectionism, work family conflict and burnout. Int. J. Bus. Soc. 2014, 5, 129-139.

72. Childs, J.H.; Stoeber, J. Do you want me to be perfect? Two longitudinal studies on socially prescribed perfectionism, stress and burnout in the workplace. Work Stress 2012, 26, 347-364. [CrossRef]

73. Hill, A.P.; Curran, T. Multidimensional perfectionism and burnout: A meta-analysis. Personal. Soc. Psychol. Rev. 2016, 20, 269-288. [CrossRef] [PubMed]

74. Park, C.L.; Adler, N.E. Coping style as a predictor of health and well-being across the first year of medical school. Health Psychol. 2003, 22, 627-631. [CrossRef]

75. Moffa, K.; Dowdy, E.; Furlong, M.J. Exploring the contributions of school belonging to complete mental health screening. Educ. Dev. Psychol. 2016, 33, 16-32. [CrossRef]

76. Kirikkanat, B.; Kali-Soyer, M. A path analysis model pertinent to undergraduates' academic success: Examining academic confidence, psychological capital and academic coping factors. Eur. J. Educ. Res. 2018, 7, 133-150. [CrossRef]

77. Kobylinska, D.; Kusev, P. Flexible Emotion Regulation: How Situational Demands and Individual Differences Influence the Effectiveness of Regulatory Strategies. Front. Psychol. 2019, 10, 72. [CrossRef]

(C) 2020 by the authors. Licensee MDPI, Basel, Switzerland. This article is an open access article distributed under the terms and conditions of the Creative Commons Attribution (CC BY) license (http://creativecommons.org/licenses/by/4.0/). 